\title{
Divergent composition but similar function of soil food webs of individual plants: plant species and community effects
}

\author{
T. M. Bezemer, ${ }^{1,2,14}$ M. T. Fountain,${ }^{3}$ J. M. Barea,${ }^{4}$ S. Christensen, ${ }^{5}$ S. C. Dekker,${ }^{6}$ H. Duyts,,${ }^{1}$ R. van Hal, ${ }^{6}$ \\ J. A. Harvey, ${ }^{1}$ K. Hedlund,${ }^{7}$ M. Maraun, ${ }^{8}$ J. Mikola,${ }^{9}$ A. G. Mladenov,${ }^{10}$ C. Robin, ${ }^{11}$ P. C. De Ruiter,,${ }^{6,12}$ \\ S. Scheu, ${ }^{8}$ H. Setälä,,${ }^{9}$ P. Šmilauer, ${ }^{13}$ and W. H. van der Putten ${ }^{1,2}$ \\ ${ }^{1}$ Department of Terrestrial Ecology, Netherlands Institute of Ecology (NIOO-KNAW), \\ P.O. Box 40, 6666 ZG Heteren, The Netherlands \\ ${ }^{2}$ Laboratory of Nematology, Wageningen University and Research Centre, P.O. Box 8123, 6700 ES Wageningen, The Netherlands \\ ${ }^{3}$ Science Department, East Malling Research, East Malling, Kent ME196BJ United Kingdom \\ ${ }^{4}$ Departamento de Microbiología del Suelo y Sistemas Simbióticos, Estación Experimental del Zaidín, \\ CSIC, Profesor Albareda, 1, 18008 Granada, Spain \\ ${ }^{5}$ Copenhagen University, Department of Terrestrial Ecology, Ø. Farimagsgade 2D, DK 1353 Copenhagen, Denmark \\ ${ }^{6}$ Department of Environmental Sciences, Copernicus Institute, Utrecht University, P.O. Box 80115, 3508 TC Utrecht, The Netherlands \\ ${ }^{7}$ Department of Ecology, Lund University, S 22362 Lund, Sweden \\ ${ }^{8}$ Georg August University of Goettingen, J.F. Blumenbach Institute of Zoology and Anthropology, Animal Ecology, \\ Berliner Strasse 28, 37073 Goettingen, Germany \\ ${ }^{9}$ Department of Ecological and Environmental Sciences, University of Helsinki, Niemenkatu 73, 15140 Lahti, Finland \\ ${ }^{10}$ Biodiversity Department, Central Laboratory of General Ecology, 2, Yurii Gagarin Street, 1113 Sofia, Bulgaria \\ ${ }^{11}$ Nancy Université, (INPL)-INRA, Agronomie et Environment, Nancy-Colmar, BP 172, F-54505 Vandoeuvre-les-Nancy, France \\ ${ }^{12}$ Soil Centre, Wageningen University and Research Centre, Droevendaalsesteeg 4, 6708 PB Wageningen, The Netherlands \\ ${ }^{13}$ Faculty of Science, University of South Bohemia, Branišovská 31, CZ-370 05 České Budéjovice, Czech Republic
}

\begin{abstract}
Soils are extremely rich in biodiversity, and soil organisms play pivotal roles in supporting terrestrial life, but the role that individual plants and plant communities play in influencing the diversity and functioning of soil food webs remains highly debated. Plants, as primary producers and providers of resources to the soil food web, are of vital importance for the composition, structure, and functioning of soil communities. However, whether natural soil food webs that are completely open to immigration and emigration differ underneath individual plants remains unknown. In a biodiversity restoration experiment we first compared the soil nematode communities of 228 individual plants belonging to eight herbaceous species. We included grass, leguminous, and non-leguminous species. Each individual plant grew intermingled with other species, but all plant species had a different nematode community. Moreover, nematode communities were more similar when plant individuals were growing in the same as compared to different plant communities, and these effects were most apparent for the groups of bacterivorous, carnivorous, and omnivorous nematodes. Subsequently, we analyzed the composition, structure, and functioning of the complete soil food webs of 58 individual plants, belonging to two of the plant species, Lotus corniculatus (Fabaceae) and Plantago lanceolata (Plantaginaceae). We isolated and identified more than 150 taxa/groups of soil organisms. The soil community composition and structure of the entire food webs were influenced both by the species identity of the plant individual and the surrounding plant community. Unexpectedly, plant identity had the strongest effects on decomposing soil organisms, widely believed to be generalist feeders. In contrast, quantitative food web modeling showed that the composition of the plant community influenced nitrogen mineralization under individual plants, but that plant species identity did not affect nitrogen or carbon mineralization or food web stability. Hence, the composition and structure of entire soil food webs vary at the scale of individual plants and are strongly influenced by the species identity of the plant. However, the ecosystem functions these food webs provide are determined by the identity of the entire plant community.
\end{abstract}

Key words: biodiversity; ecosystem function; food web composition; food web model; Lotus corniculatus; macrofauna; mesofauna; microfauna; Plantago lanceolata; soil biota.

Manuscript received 25 November 2009; revised 17 February 2010; accepted 18 February 2010. Corresponding Editor (ad hoc): D. S. Gruner.

${ }^{14}$ E-mail: m.bezemer@nioo.knaw.nl

\section{INTRODUCTION}

Terrestrial habitats harbor an immense diversity of soil biota and a square meter of grassland may contain more 10000 taxa (Bardgett 2005). Understanding the drivers and the functional consequences of this belowground biodiversity is one of the major challenges of 
contemporary ecology (Bardgett 2005, Wardle 2006). For a long time, the existing paradigm has been that most soil organisms are generalists and are relatively insensitive to the identity of the plant species that provide the resources (Wardle 2002). However, plant species vary in their impact on soil organisms through differences in the quantity and quality of organic matter that they produce (Grayston et al. 1998, Bardgett et al. 1999, Wardle et al. 2004). Moreover, plants have species-specific feedback interactions with their soil communities (van der Putten et al. 1993, Bever 2003), effected via root feeders, mutualistic symbionts, and decomposer organisms, alone or in combination (Wardle et al. 2004). The specificity of these plant-soil feedback interactions implies that soil communities associated with different plant species may vary distinctly. To this point, however, little is known about how individual plants in a community may differ in their soil food web structure and how this affects the flows of nutrients and energy processed below ground.

In natural plant communities, individual plants grow intermingled with conspecific and heterospecific plants. Since soil food webs under individual plants are open to immigration and emigration of soil organisms, both the identity of the plant and the composition and density of the surrounding plant community might influence soil food web structure and functioning. Plant removal studies in grasslands support the view that changes in plant community composition have little impact on the average composition of the soil community (Wardle et al. 1999). Plant diversity experiments, on the other hand, have shown that plant species or functional groups of plants differ in their effects on specific components of the soil community (Porazinska et al. 2003, Zak et al. 2003, De Deyn et al. 2004, Viketoft et al. 2009). These studies typically use 'homogenized' soil collated from a number of soil samples to determine soil community composition. Whether soil food webs underneath individual plants differ in composition or functioning remains largely unknown.

We quantified the soil food webs and their functioning beneath individual plants of different species and examined the effects of the surrounding plant community on the soil food webs of individual plants. The plants were growing in plots that were originally sown with four or fifteen grassland species, or were not sown, in a unique seven-year-old grassland experiment. Afterward, colonization from the seed bank and the surrounding habitat was allowed in all plots. The plots were occupied by the same pool of plant species, however, the experimental treatments resulted in longterm consistent differences in plant community composition and ecosystem functions between the plots (Fukami et al. 2005, Bezemer and van der Putten 2007).

We determined the composition of the soil nematode community underneath 228 individual plants belonging to eight species growing in the plots. We expected that differences in soil community composition between the plant species would be greatest for root-feeding nematodes, as they interact directly with living root tissue. Nematodes inhabit a range of trophic positions within the soil food web and interact with plant roots as well as soil microorganisms and invertebrates (Yeates et al. 1993). For two of the plant species, Plantago lanceolata (ribwort plantain) and Lotus corniculatus (bird's-foot trefoil) we then determined the entire soil food web beneath the individual plants and determined the influence of host plant and plant community identity. Both $P$. lanceolata and L. corniculatus are perennial forbs that differ greatly in the quantity and quality of resource input (Bischoff et al. 2006). L. corniculatus is a legume capable of fixing atmospheric nitrogen and, therefore, produces biomass of relatively high nitrogen concentration. P. lanceolata is a non-leguminous forb that contains iridoid glycosides that are toxic to many invertebrate consumers (Bowers et al. 1992). In order to determine possible consequences for ecosystem processes and properties, we subsequently used a quantitative model (de Ruiter et al. 1995) to analyze carbon and nitrogen mineralization and food web stability in each individual food web. We expected that mineralization rates and stability would depend on the identity of the plant species.

\section{Methods}

In spring 1996, a field experiment was set up on $100 \times$ $50 \mathrm{~m}$ of formerly arable land at Planken Wambuis, Ede, The Netherlands (see Plate 1). The field was abandoned after harvesting the last crop in the fall of 1995. The total area of previously arable land was approximately 55 ha and the surrounding area consisting of heath land, mixed forest, and arable land that was abandoned 10 years earlier. The soil was a sandy-loam soil with particle size distribution: $<2 \mu \mathrm{m}, 3.4 \%$; $2-63 \mu \mathrm{m}, 17.3 \%$; $>63 \mu \mathrm{m}, 79.7 \%$. At the beginning of the experiment all vegetation was removed and the field was harrowed with a cultivator. The experimental treatments were installed using a randomized block design with five blocks. Each block contained one replicate $10 \times 10 \mathrm{~m}$ plot for each sowing level $(15,4$, or 0 species [unsown]). Within each block, the plots were separated by lanes $2 \mathrm{~m}$ wide that were mown frequently. All replicates with 15 species sown had the same combination of species (five grasses, five legumes, five non-leguminous forbs; Appendix A: Table A1; Appendix C: Photograph C1). All sown species were originally absent when the field was abandoned. Each of the replicates with four sown species had a different subset of the high diversity mixture (two grasses, one legume, one non-leguminous forb; Appendix A: Table A1). Details about the experimental design and sowing treatments have been described elsewhere (van der Putten et al. 2000).

After sowing, plots were not weeded, so that the communities were the result of self-assemblage following initial sowing. Plants could colonize from the area surrounding the experimental field but also from other 
plots. At the end of each growing season (September/ October), all plots were mown and the aboveground biomass was removed. From 1996 to 2003, the three sowing treatments differed consistently and substantially in productivity, plant species composition, and diversity (Bezemer et al. 2006a; see Appendix A: Table A2 for plant community properties in 2003 , the sampling year). However, many plant species, including $P$. lanceolata (ribwort plantain) and L. corniculatus (bird's-foot trefoil) spread rapidly from sown plots to other plots where they were absent initially.

In early June 2003, in each plot, we sampled two individuals of eight different plant species belonging to three different functional groups: grasses (Festuca rubra, Holcus lanatus, Anthoxanthum odoratum), non-leguminous forbs (Leucanthemum vulgare, Plantago lanceolata, Tanacetum vulgare), and legumes (Vicia cracca, Lotus corniculatus). All species, except $H$. lanatus and $L$. vulgare were originally sown. We took a soil core (diameter $5 \mathrm{~cm}$, depth $10 \mathrm{~cm}$ ) at the base of each plant and extracted the nematodes. Not all plant species were present in all plots, but we always sampled two individuals in plots where the species were present $(F$. rubra, 14 plots; H. lanatus, 14 plots; A. odoratum, 15 plots; L. vulgare, 14 plots; P. lanceolata, 15 plots; $T$. vulgare, 13 plots; $V$. cracca, 15 plots; L. corniculatus, 14 plots).

One week later, two different individuals of the plant species $L$. corniculatus and $P$. lanceolata were randomly selected in each plot. These two sown plant species had colonized all plots but one: a plot sown with four species that was not colonized by L. corniculatus (block 5). This resulted in a total of 58 plants that were excavated by removing $15 \times 15 \times 15 \mathrm{~cm}$ soil blocks. Roots and soil of surrounding plants and the soil adhered to them were first removed so that only the roots and rhizosphere soil (soil surrounding the roots) of the sampled plants remained. Two soil cores $(5 \mathrm{~cm}$ diameter, $10 \mathrm{~cm}$ depth) were then collected near the stem base of each plant; one for extraction of enchytraeid worms, and one for extraction of soil mites, Collembola, and other invertebrates. Subsamples of the remaining rhizosphere soil were used to determine microbial biomass by analyzing neutral and phospholipid fatty acids, to extract nematodes, spores of arbuscular mycorrhizal fungi, and protozoa, and to determine microbial substrate utilization pattern using a BIOLOG microplate (Garland 1996). Soil samples were hand-sieved to extract larger insects, spiders, earthworms, and mollusks. Roots of each plant were washed, oven-dried at $70^{\circ} \mathrm{C}$, and their dry mass determined. Biomass of soil organisms was expressed as grams carbon per gram soil. Protocols for extraction of soil organisms are provided in Appendix B.

\section{Data analyses}

Nematode communities of individuals of the eight plant species were compared using similarity analysis. We calculated the Bray-Curtis similarity between two plants of the same or a different species that were growing in the same plot, or between two plants growing in two different plots. The similarities for each of the four categories were averaged for each individual plant and these values were analyzed using linear mixed model analyses in Genstat 11 (Payne et al. 2008). This type of analysis calculates Wald-type $F$ statistics that are asymptotically equivalent to standard $F$ statistics, and can process different sources of variation (Payne et al. 2008). The requirements for normality and homogeneity of variance were fulfilled. Data were analyzed with plot as random factor and species identity (same or different) and plot identity (same or different) and their interaction as fixed factors. For each plant species we also calculated the similarity between two nematode communities of plants originating from the same plot and belonging to the same functional group (grasses, legumes, non-leguminous forbs), or to two different functional groups. Mean values per plot (same or different functional group) were then compared using a $t$ test. We used multivariate redundancy analysis (RDA) using Canoco for Windows 4.5 (ter Braak and Šmilauer 2002) to compare nematode community composition. Within each plot we determined whether the nematode community of a plant species differed significantly from that of the other plant species using a Monte Carlo permutation test restricted for block design (999 permutations). We subsequently separated the nematode communities into (1) plant feeders, (2) fungal feeders, (3) bacterial feeders, and (4) omnivores and carnivores, and analyzed the composition of these groups separately.

For comparisons of food webs of $P$. lanceolata and $L$. corniculatus, we analyzed taxonomic composition using multivariate techniques. Effects of studied factors (host plant species identity, host plant biomass, sowing treatment, plot identity, and the interaction between sowing treatment and plant species identity) on taxonomic composition of individual groups were described using multivariate canonical correspondence analysis (CCA). Biomass of all feeding groups of the entire soil food web was analyzed using constrained linear analysis (RDA). Data were analyzed using Canoco for Windows 4.5. Significance of the effects was tested using Monte Carlo permutation tests, with their set-up varying with the tested factor, in dependence on its role in the hierarchical experimental design. Host plant identity effects were tested using partial CCA with the plot identity as covariate. The sowing treatment effect was tested using an analysis with species identity as covariate and holding together the pairs of observations representing two individuals from the same plot.

Univariate data (biomass of soil organisms and results of food web modeling) were analyzed using linear mixed model analyses. All data were checked for normality and homogeneity of variance and log-transformed when appropriate. Data were analyzed with host plant species, 


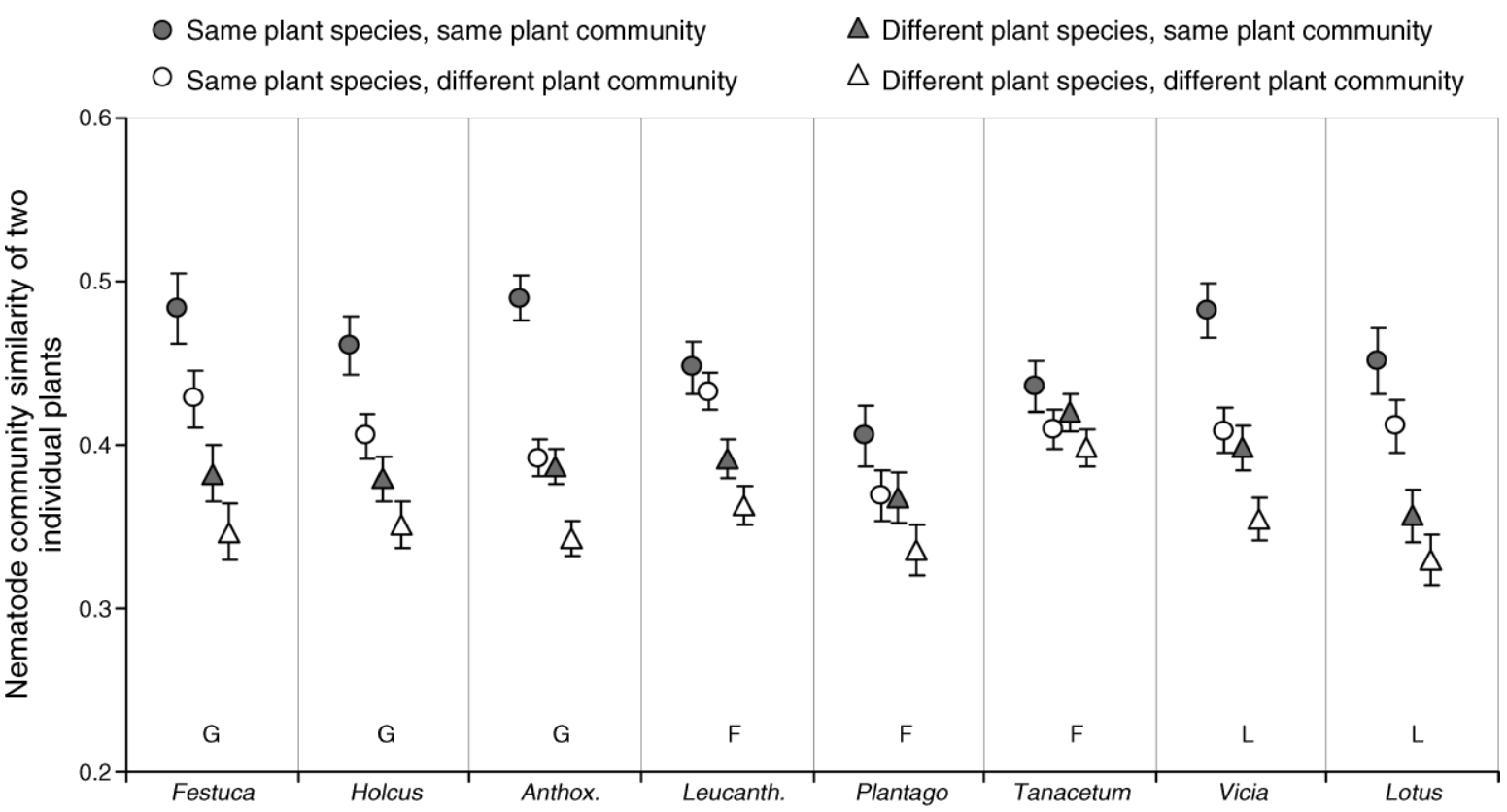

FIG. 1. The composition of nematode communities underneath individual plants is influenced by the identity of the plant species and by the plant community in which the species was embedded. For eight different plant species a consistent pattern emerges: The similarity (Bray-Curtis) between two nematode communities is highest when two plant individuals of the same species and growing in the same plant community are compared, and lowest when two plants belonging to two different plant species and growing in two different plant communities are compared. Means are shown with standard errors for plant individuals of grass species (G) Festuca rubra, Holcus lanatus, and Anthoxanthum odoratum (Anthox.); forb species (F) Leucanthemum vulgare (Leucanth.), Plantago lanceolata, and Tanacetum vulgare; and legume species (L) Vicia cracca and Lotus corniculatus.

sowing treatment and their interaction as fixed effects and plot identity as random factor.

\section{Food web modeling}

Feeding rates were calculated for each functional group by assuming that the annual average production of the group balances the rate of loss through natural death and predation (Hunt et al. 1987) and were based on the relative abundance of the prey groups and on the preferences of the predators. Parameters are from Hunt et al. (1987). Interaction strengths were calculated as the partial derivative of the Lotka-Volterra equations of the species (de Ruiter et al. 1995), while if detritus was involved, excretion of all functional groups was added, according to Moore et al. (1993). A food web is considered stable if all maximum real eigenvalues of the interaction strength matrix are negative $\left(\lambda_{\max }<0\right.$; May 1973). We quantified stability in terms of the minimum degree of intraspecific interaction needed for matrix stability ( $s$, dimensionless; de Ruiter et al. 1995). The closer $s$ is to zero the more stable the food web is. Maximum loop weight is a measure for the patterning of interaction strength over trophic levels and was calculated to relate food web structure to stability (Neutel et al. 2002). A trophic interaction loop is an omnivorous chain of interactions between feeding groups starting and ending with the same trophic feeding group. The length of a loop is made up by the number of trophic groups that is included in the loop. The weight of a loop was calculated as the geometric mean of the interaction strengths in the loop. We calculated maximum loop weight only for loops of three and longer, as loops of length two are not important for stability (Neutel et al. 2002). The loop with the maximum loop weight was named the critical loop. The critical loop changes during the course of succession when food web complexity increases (Neutel et al. 2007) and is, therefore, indicative of soil food web structure.

\section{RESUlts}

For all plant species, nematode community similarity (Bray-Curtis) was highest when we compared individuals from the same species that were growing in the same plant community. The similarity was less when comparing individuals of the same species that were growing in different plant communities, and was lowest for plants belonging to different species and growing in different plant communities (Fig. 1). For all species, except for $T$. vulgare, this resulted in significant plant species and plant community effects (comparison of similarities among the same or different plant species/ communities; Appendix A: Table A3). For all eight plant species, nematode communities of two plants belonging to the same functional group were not more similar than nematode communities of two plants belonging to different functional groups. Moreover, for F. ovina, A. odoratum, T. vulgare, and $V$. cracca, nematode community similarity was significantly higher when two plants 


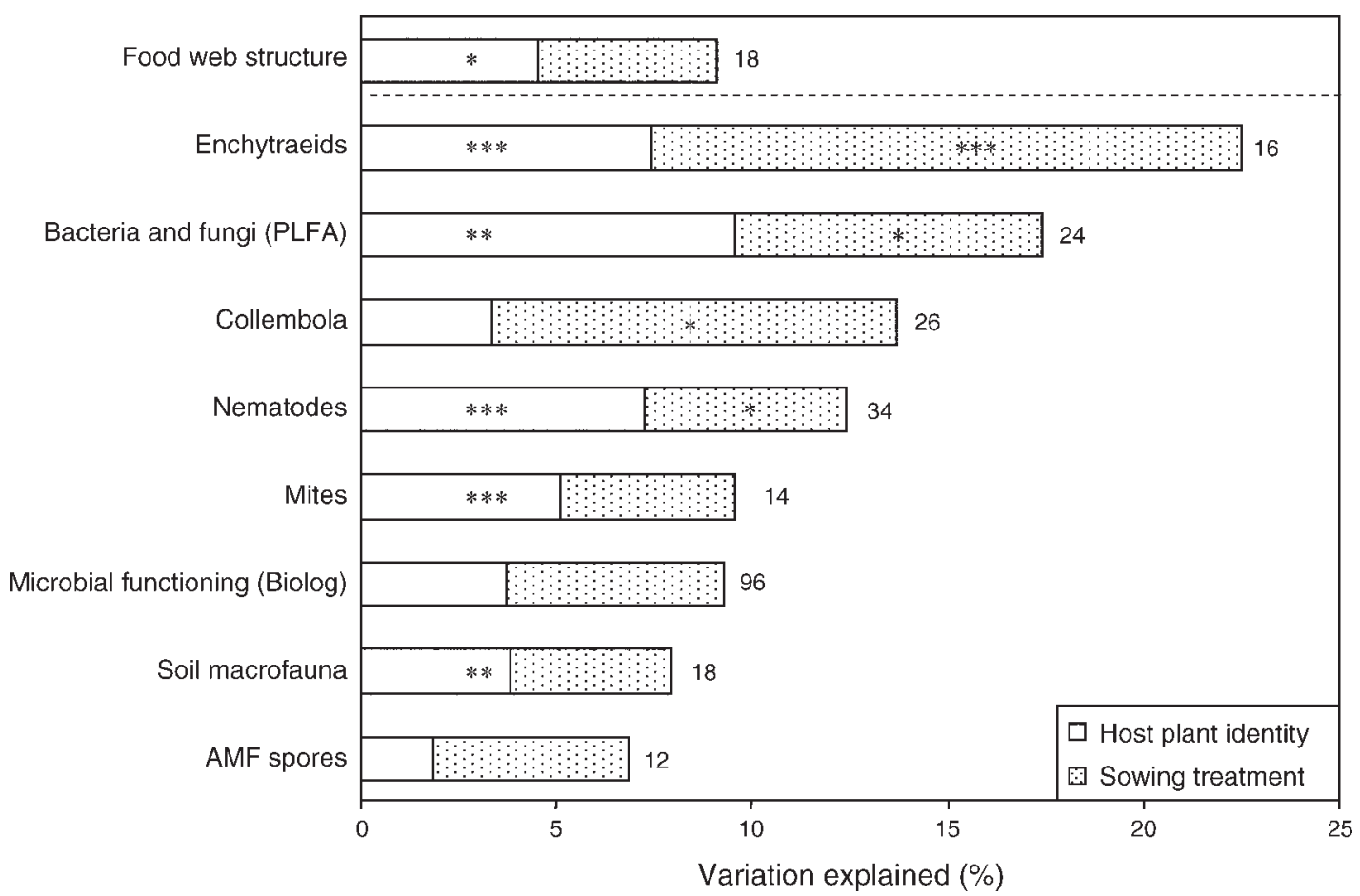

FIG. 2. Plant species identity (L. corniculatus or P. lanceolata) and surrounding plant community (originally sown with 15 , 4 , or 0 species) influence the composition of soil communities underneath individual plants. Results are from multivariate analyses of the composition of different taxonomic groups of soil organisms, phospholipids (PLFA), and microbial functioning (Biolog), and on the food web structure (the composition of the carbon biomasses of all feeding groups within the food web as depicted in Fig. 4); AMF stands for arbuscular mycorrhizal fungi. The amount of variation within the 58 food webs that is explained by host plant identity $(\mathrm{df}=1)$ and plant community identity (sowing treatment, $\mathrm{df}=2$ ) is shown. The number following each bar shows the number of identified categories (e.g., species or genus) included in the analysis. Asterisks indicate significance of the effect based on permutation tests.

* $P<0.05$; ** $P<0.01$; *** $P<0.001$.

from different functional groups were compared. All plant species had a unique nematode community associated with their roots, which significantly differed from that of other species (Appendix A: Table A4). Remarkably, except for nematode communities of the plant species $H$. lanatus and $L$. corniculatus, these differences were not significant for root-feeding nematodes which directly interact with live plant tissues. However, for the groups of bacterial feeders and omnivores and carnivores the effects were highly significant for all plant species (Appendix A: Table A5).

For 30 P. lanceolata and 28 L. corniculatus plants, we determined the entire food web under each plant. We collected soil cores and isolated and identified $>150$ taxa or groups of soil organisms (Appendix A: Table A6). Individual plant biomass differed more than 30 -fold for each of the two species, but in none of the groups of soil organisms did we find a significant effect of host plant biomass on soil community composition (Appendix A: Table A7). However, although the plants grew intermingled with other plants (Appendix C: Photograph C2), we observed significant effects of both plant species and community identity on the composition of soil organisms. The community composition of mites, enchytraeid worms, nematodes, soil macrofauna, and phospholipid fatty acid patterns, which are indicative of microbial diversity, all differed between the two plant species (Fig. 2; Appendix D: Fig. D1). The composition of spore morphotypes of arbuscular mycorrhizal fungi (AMF), which form specific mutualistic associations with plant roots (Smith and Read 1997), and Collembola was not influenced by the identity of the host plant. It is especially noteworthy that of the 16 enchytraeid species recorded, five were exclusively associated with $L$. corniculatus, and four other species exclusively with $P$. lanceolata plants (Appendix A: Table A8). Moreover, enchytraeid abundance and richness responded differently in the two plant species (Fig. 3; Appendix A: Table A9). These results indicate that this group of secondary consumers has specialized plant preferences. We also detected plant community effects (Appendix A: Table A7) and sowing treatment effects (Fig. 2) on the composition of soil organisms underneath individual host plants. For enchytraeids, seven species were observed only in one of the three sowing treatments, while another five species were only found in two of the three sowing treatments (Appendix A: Table A8). 

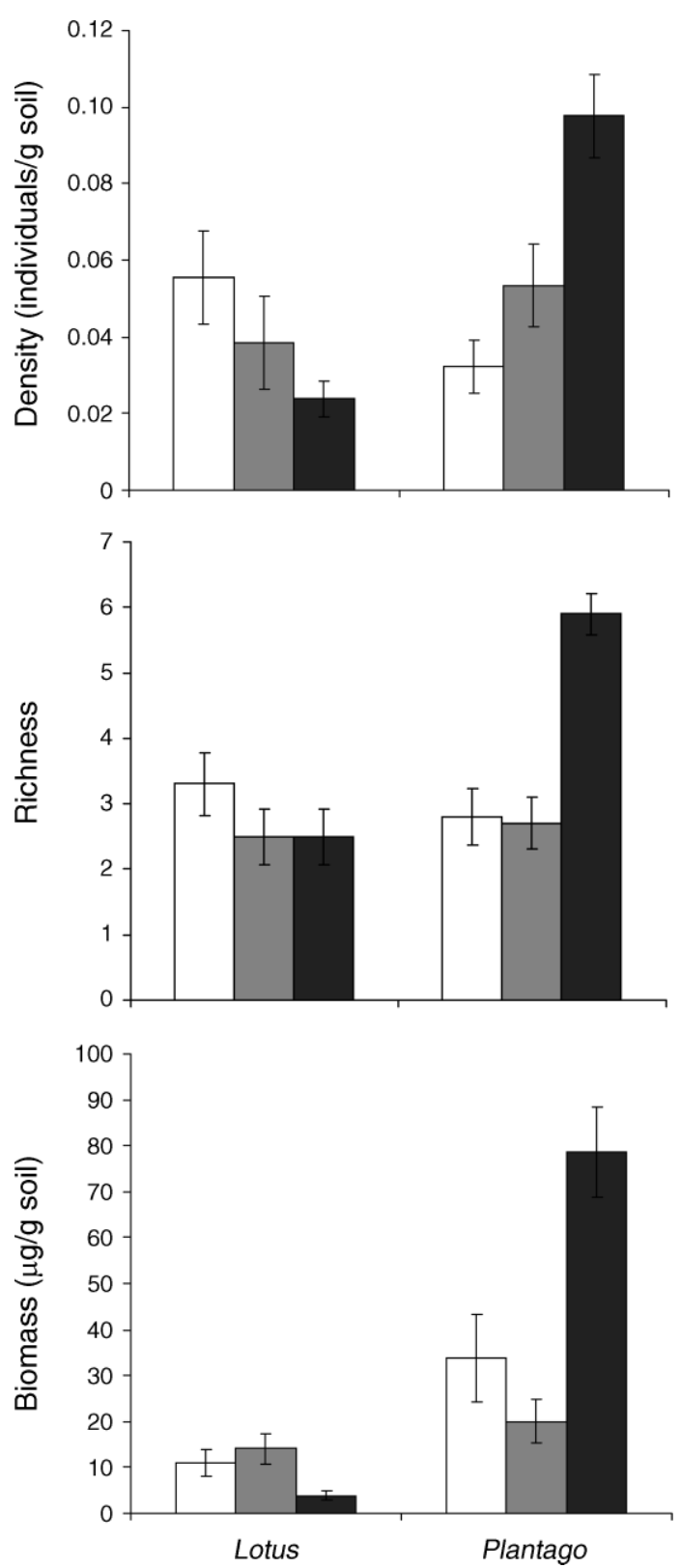

FIG. 3. Enchytraeid density, richness, and biomass in the rhizosphere of individual $L$. corniculatus and $P$. lanceolata plants that were growing in plant communities originally sown with 15 (white bars) or four (gray bars) species, or that were not sown (black bars). Means are shown \pm standard errors.

To determine possible consequences of the differences in soil community composition on soil food web structure, we converted the abundance of each taxon into carbon biomass and allocated the identified taxa into feeding groups (Appendix A: Table A6). We expected that lumping soil organisms into broad feeding groups would reduce the power to detect effects of plant species or sowing treatments.

Based on current knowledge of their feeding habits, we assembled a total of 18 categories of feeding groups
(Fig. 4). We also included the two types of basal resources, namely roots and soil organic matter. $L$. corniculatus plants had substantially more root biomass per gram of soil than did $P$. lanceolata plants (Wald $F=$ 20.52 , df $=1,42, P<0.001)$, but the amount of soil organic matter did not differ between the two plant species (Appendix D: Fig. D2). Within each food web, fungi, bacteria and earthworms contributed the most to the total biomass (Fig. 4). Multivariate analyses of the complete soil food web showed that food web structure, expressed as biomass distribution among the 18 feeding groups, varied significantly between the food webs belonging to individuals of the two plant species (Fig. 2). Moreover, when the biomass of the individual feeding groups was analyzed separately, a number of these groups at various positions within the soil food web differed between the two plant species and/or the composition of the surrounding plant community (Appendix D: Fig. D2). Particularly noteworthy were differences in enchytraeid biomass, which was considerably higher in communities associated with $P$. lanceolata than $L$. corniculatus, but also depended on the surrounding plant community (Fig. 3).

Subsequently, we determined the possible consequences of the differences in the individual-plant food webs for ecosystem processes (rates of carbon and nitrogen mineralization) and properties (stability of the soil food web). We used a soil food web model based on feeding links between individual feeding groups to calculate carbon and nitrogen mineralization, as well as food web stability and the position of the critical loop, which identifies the weakest link in determining the stability of the food web. Carbon mineralization was not influenced by plant species or by plant community identity, but nitrogen mineralization differed significantly between the plant communities from the different sowing treatments (Appendix A: Table A10). Modeled nitrogen mineralization was, on average, lowest underneath plants growing in plots that had originally been sown with four plant species and highest for plants growing in unsown plots (Appendix D: Fig. D3). Food web stability was not influenced by the species identity of the individual plant or by plant community identity. However, plant species identity had a significant effect on the position of the critical loop in the soil food web. The critical loop was situated in the bacterial channel in 45 of 58 webs, and this occurred mostly in soil food webs of $P$. lanceolata $(P=0.008$; Appendix A: Table A11). These results show that even within one plant community, the critical loop of interactions in soil food webs can vary among plant species.

\section{Discussion}

Our results with nematode communities beneath individual plants of eight different species, and entire food webs for two of those plant species are remarkably consistent. There is a clear hierarchy in the plant 


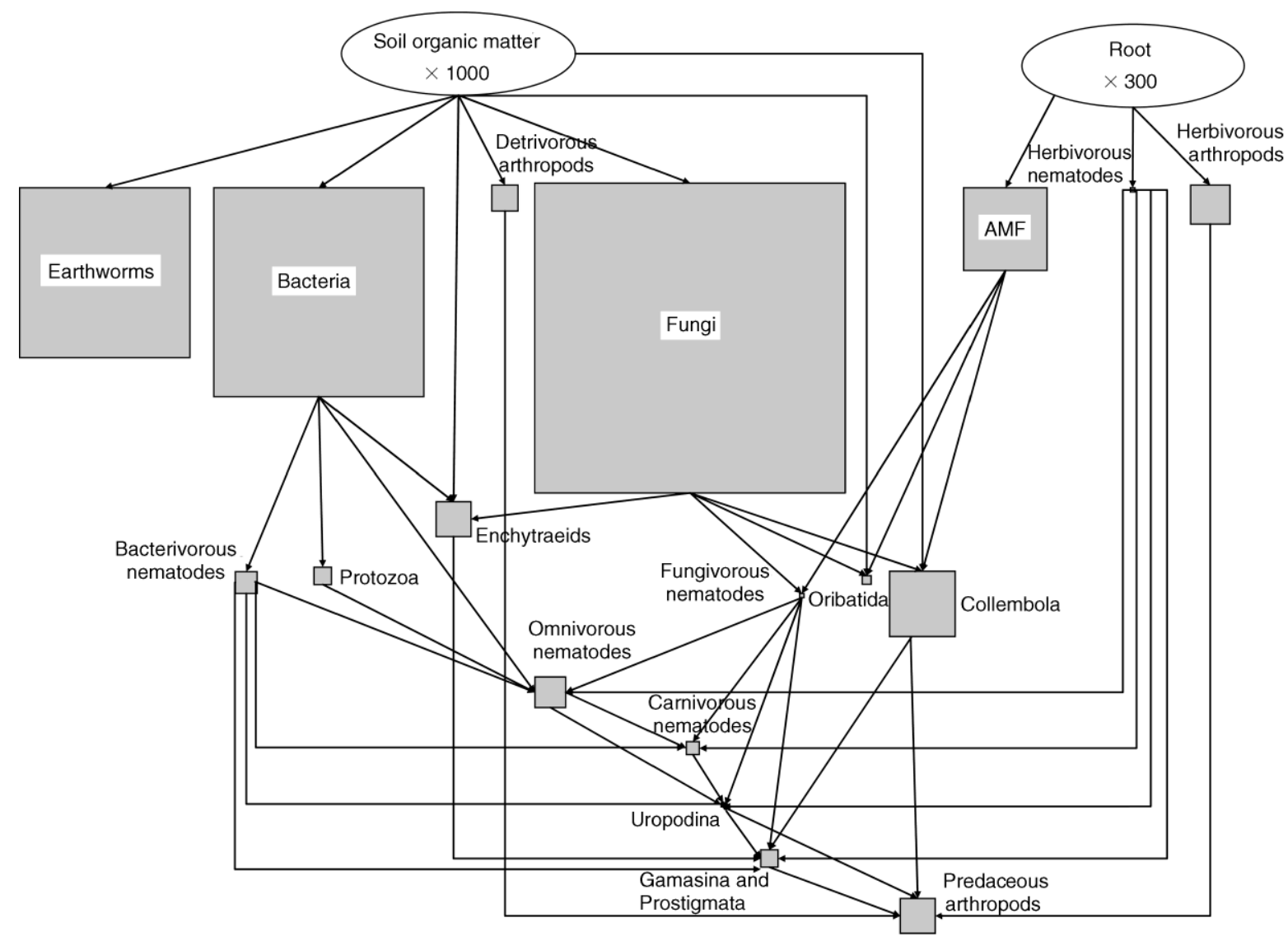

FIG. 4. Schematic representation of the soil food web. Soil organisms were grouped into feeding groups, and the biomass of each group was calculated ( $\mathrm{g}$ carbon per $\mathrm{g}$ soil). Boxes represent feeding groups, and their surface areas represent feeding group biomass, based on the average of all food webs. Biomass of roots and soil organic matter are not scaled to their actual amounts, but the ratio is shown. Arrows indicate feeding relations with the arrow head pointing toward the consumer. AMF stands for arbuscular mycorrhizal fungi.

community-related factors that determine the composition of soil food webs and the scale at which they operate. In natural systems that are completely open and with plants that grow intermingled, the identity of the plant individual still has the most significant impact on the composition of the soil community. These results resemble patterns observed in aboveground food webs, and have been explained by differences in morphological, chemical, and phenological plant traits between plant species (Whitham et al. 1999). Similarly, it is plausible that species-specific differences in plant root traits (such as differences in secondary compounds in root tissues, root exudates, or litter) contributed to the differences that we observed in soil community composition underneath the individual plants. Soil organisms are far less mobile than aboveground insects and soil organisms generally migrate slowly between food resources in soil (Christensen et al. 2007). Therefore, we may expect that below ground, the identity of neighboring plants, and plants previously occupying that particular position will also influence to the composition of the soil community underneath a plant individual. Indeed, in our study, we observed a significant effect of the plant community in which the individual plant was growing on the composition of the soil community.

Our study shows that for multispecies plant communities, soil food webs constructed at the field scale do not reveal the true scale at which plants generate local soil food webs. The conclusion that a multispecies plant community does not have a single soil food web, but that individual plants have their own soil food web is an important new step in further unraveling spatial dynamics of belowground communities (Ettema and Wardle 2002). It also helps to explain why an increasing number of studies report specific patterns in plant-soil feedback (Bever 2003, Kulmatiski et al. 2008). More studies are needed that test spatial heterogeneity of plant-soil interactions (Bezemer et al. 2006b, Casper and Castelli 2007).

Plant species can differ in their microbial rhizosphere communities (Grayston et al. 1998). Our results from local food webs show that these differences can also be observed in other, non-microbial taxa that have indirect 


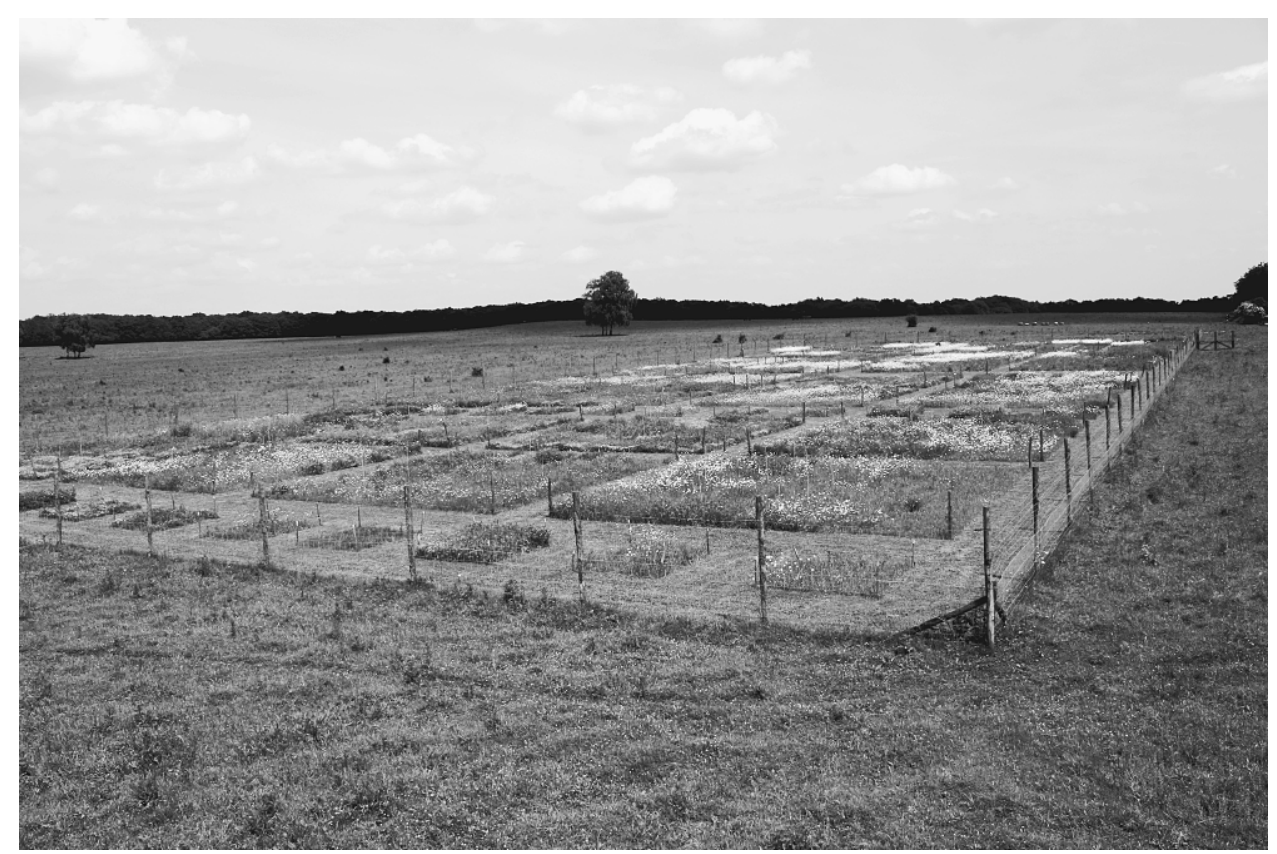

Plate 1. The experimental field site and the surrounding nature restoration area "Planken Wambuis" in The Netherlands. Photo credit: T. M. Bezemer.

interactions with live plant roots. For the eight plant species, the strongest differences between species were observed in the groups of bacterial feeders and omnivores/carnivores, which are considered to be generalistic feeders (Yetates et al. 1993). The food webs of P. lanceolata and L. corniculatus were most different in enchytraeid species composition; however, these are considered generalist feeders on dead plant material and microorganisms feeding on this material (Didden 1993, Briones and Ineson 2002). Thus, we show that plant effects may trickle up to higher trophic level organisms, even in the decomposer subsystem. From aboveground work it is well known that subtle differences in plant quality can affect the performance of consumers even up to secondary consumers at higher trophic levels without plant-mediated effects on the primary consumers (Soler et al. 2005). In our study, plant quality also may have affected higher trophic level soil organisms, for example due to the effects of secondary plant compounds, such as iridoid glycosides on root herbivores without directly affecting the root herbivores themselves. An alternative explanation for the absence of plant species effects on the abundance of root feeding nematodes in our study with eight plant species, is that plant quality affected individual performance of root feeders, but that this, in turn, was compensated for by altered predation.

Although we observed strong effects of plant species identity on the composition of food webs, in none of the groups of soil organisms did we find a significant effect of biomass of the host plant, while this differed more than 30 -fold for both species. This suggests that the community composition of soil food webs under individual plants is influenced more by resource quality, represented by plant species identity, than by resource quantity (Wardle 2002). However, we expressed densities and biomasses of soil organisms per gram soil. Large plants had more soil associated with their root system than smaller individuals. Thus, there will be more soil organisms underneath a larger plant, and a large plant may contribute more to the composition of the entire soil food web within a plant community.

We detected significant differences between food webs of the two plant species growing in the three sowing treatments. This is interesting, because the sowing took place seven years earlier, and after sowing, the plots were not weeded. All other plant species colonizing the plots originated from the seed bank and the surrounding vegetation. As a result, the vast majority of plant species were present in plots from all three treatments but at different densities and with different temporal dynamics (Bezemer and van der Putten 2007). Clearly, the initial sowing treatments had long-lasting effects on the composition of the soil community, providing additional evidence that plant communities have a significant effect on the soil community composition underneath individual plants growing in those plant communities.

The soil food web modeling showed that predicted food web functions also differed in plant communities established from the three sowing treatments. Nitrogen mineralization was highest for plants in plots that were not sown. Since these plots also had the highest number of plant species (Bezemer and van der Putten 2007), our data suggest that high plant diversity corresponds with high nitrogen mineralization. Similar results have been 
reported from biodiversity experiments where, in contrast to our study, plant species richness and composition were maintained by hand weeding (e.g., Spehn et al. 2002, Zak et al. 2003).

We conclude that the composition of soil communities underneath individual plants is influenced by the identity of the plant species as well as by the surrounding plant community. However, the identity of the host plant does not apparently influence the functioning of those soil food webs. Thus, the identity of the individual plant, as well as that of the entire plant community affects the spatial structure and diversity of soil food webs. This provides an additional explanation for the spatial heterogeneity and sheer diversity of soil organisms observed in natural systems. The results are relevant for the restoration and conservation of plant and aboveground biodiversity. Initial decisions on management after land abandonment, for example whether to sow target plants or not, can greatly determine the feedback dynamics between plant and soil communities. As plant-soil feedback interactions influence plant community structure and diversity (Wardle et al. 2004), as well as belowground-aboveground interactions (Bezemer et al. 2005), our results suggest that initial decisions on plant community restoration may have long-lasting effects on belowground, as well as aboveground biodiversity conservation.

\section{ACKNOWLEDGMENTS}

We thank Natuurmonumenten (NL) for allowing us to establish the field experiment and two anonymous reviewers for their constructive comments on an earlier version of the manuscript. This study is supported by the European Commission under FP5 Contract nr: EVK2-CT-2001-00254. T. M. Bezemer is funded by the Netherlands Organization for Scientific Research (NWO, VIDI grant no 864.07.009), and P. Šmilauer by a grant from the Czech Ministry of Education, MSM-6007665801. This is NIOO publication 4746.

\section{Literature Cited}

Bardgett, R. D. 2005. The biology of soils: a community and ecosystem approach. Oxford University Press, Oxford, UK.

Bardgett, R. D., J. L. Mawdsley, S. Edwards, P. J. Hobbs, J. S. Rodwell, and W. J. Davies. 1999. Plant species and nitrogen effects on soil biological properties of temperate upland grasslands. Functional Ecology 13:650-660.

Bever, J. D. 2003. Soil community feedback and the coexistence of competitors: conceptual frameworks and empirical tests. New Phytologist 157:465-473.

Bezemer, T. M., G. B. De Deyn, T. M. Bossinga, N. M. van Dam, J. A. Harvey, and W. H. van der Putten. 2005. Soil community composition drives aboveground plant-herbivore-parasitoid interactions. Ecology Letters 8:652-661.

Bezemer, T. M., J. A. Harvey, G. A. Kowalchuk, H. Korpershoek, and W. H. van der Putten. 2006a. Interplay between Senecio jacobaea and plant, soil, and aboveground insect community composition. Ecology 87:2002-2013.

Bezemer, T. M., C. S. Lawson, K. Hedlund, A. R. Edwards, A. J. Brook, J. M. Igual, S. R. Mortimer, and W. H. van der Putten. 2006b. Plant species and functional group effects on abiotic and microbial soil properties and plant-soil feedback responses in two grasslands. Journal of Ecology 94:893-904.

Bezemer, T. M., and W. H. van der Putten. 2007. Ecology: diversity and stability in plant communities. Nature 446:E6E7.
Bischoff, A., et al. 2006. Detecting local adaptation in widespread grassland species: the importance of scale and local plant community. Journal of Ecology 94:1130-1142.

Bowers, M. D., S. K. Collinge, S. E. Gamble, and J. Schmitt. 1992. Effects of genotype, habitat, and seasonal variation on iridoid glycoside content of Plantago lanceolata (Plantaginaceae) and the implications for insect herbivores. Oecologia 91:201-207.

Briones, M. J. I., and P. Ineson. 2002. Use of C-14 carbon dating to determine feeding behaviour of enchytraeids. Soil Biology and Biochemistry 34:881-884.

Casper, B. B., and J. P. Castelli. 2007. Evaluating plant-soil feedback together with competition in a serpentine grassland. Ecology Letters 10:394-400.

Christensen, S., J. Alphei, M. Vestergard, and P. Vestergard. 2007. Nematode migration and nutrient diffusion between vetch and barley material in soil. Soil Biology and Biochemistry 39:1410-1417.

De Deyn, G. B., C. E. Raaijmakers, J. Van Ruijven, F. Berendse, and W. H. van der Putten. 2004. Plant species identity and diversity effects on different trophic levels of nematodes in the soil food web. Oikos 106:576-586.

de Ruiter, P. C., A. M. Neutel, and J. C. Moore. 1995. Energetics, patterns of interaction strengths, and stability in real ecosystems. Science 269:1257-1260.

Didden, W. A. M. 1993. Ecology of terrestrial Enchytraeidae. Pedobiologia 37:2-29.

Ettema, C. H., and D. A. Wardle. 2002. Spatial soil ecology. Trends in Ecology and Evolution 17:177-183.

Fukami, T., T. M. Bezemer, S. R. Mortimer, and W. H. van der Putten. 2005. Species divergence and trait convergence in experimental plant community assembly. Ecology Letters 8: $1283-1290$.

Garland, J. L. 1996. Analytical approaches to the characterization of samples of microbial communities using patterns of potential C source utilization. Soil Biology and Biochemistry 28:213-221.

Grayston, S. J., S. Q. Wang, C. D. Campbell, and A. C. Edwards. 1998. Selective influence of plant species on microbial diversity in the rhizosphere. Soil Biology and Biochemistry 30:369-378.

Hunt, H. W., D. C. Coleman, E. R. Ingham, R. E. Ingham, E. T. Elliott, J. C. Moore, S. L. Rose, C. P. P. Reid, and C. R. Morley. 1987. The detrital food web in a shortgrass prairie. Biology and Fertility of Soils 3:57-68.

Kulmatiski, A., K. H. Beard, J. R. Stevens, and S. M. Cobbold. 2008. Plant-soil feedbacks: a meta-analytical review. Ecology Letters 11:980-992.

May, R. M. 1973. Stability and complexity in model ecosystems. Princeton University Press, Princeton, New Jersey, USA.

Moore, J. C., P. C. de Ruiter, and H. W. Hunt. 1993. Influence of productivity on the stability of real and model ecosystems. Science 261:906-908.

Neutel, A. M., J. A. P. Heesterbeek, and P. C. de Ruiter. 2002. Stability in real food webs: weak links in long loops. Science 296:1120-1123.

Neutel, A. M., J. A. P. Heesterbeek, J. van de Koppel, G. Hoenderboom, A. Vos, C. Kaldeway, F. Berendse, and P. C. de Ruiter. 2007. Reconciling complexity with stability in naturally assembling food webs. Nature 449:599-602.

Payne, R. W., S. A. Harding, D. A. Murray, D. M. Soutar, D. B. Baird, S. J. Welham, A. F. Kane, A. R. Gilmour, R. Thompson, R. Webster, and G. Tunnicliffe Wilson. 2008. The guide to GenStat Release 11. Part 2: statistics. VSN International, Hemel Hempstead, UK.

Porazinska, D. L., R. D. Bardgett, M. B. Blaauw, H. W. Hunt, A. N. Parsons, T. R. Seastedt, and D. H. Wall. 2003. Relationships at the aboveground-belowground interface: plants, soil biota, and soil processes. Ecological Monographs 73:377-395. 
Smith, S. E., and D. J. Read. 1997. Mycorrhizal symbiosis. Second edition. Academic Press, London, UK.

Soler, R., T. M. Bezemer, W. H. van der Putten, L. E. M. Vet, and J. A. Harvey. 2005. Root herbivore effects on aboveground herbivore, parasitoid and hyperparasitoid performance via changes in plant quality. Journal of Animal Ecology 74:1121-1130.

Spehn, E. M., et al. 2002. The role of legumes as a component of biodiversity in a cross-European study of grassland biomass nitrogen. Oikos 98:205-218.

ter Braak, C. J. F., and P. Šmilauer. 2002. CANOCO reference manual and CanoDraw for Windows user's guide. Software for canonical community ordination, version 4.5. Microcomputer Power, Ithaca, New York, USA.

van der Putten, W. H., et al. 2000. Plant species diversity as a driver of early succession in abandoned fields: a multi-site approach. Oecologia 124:91-99.

van der Putten, W. H., C. Van Dijk, and B. A. M. Peters. 1993. Plant-specific soil-borne diseases contribute to succession in foredune vegetation. Nature 362:53-56.

Viketoft, M., J. Bengtsson, B. Sohlenius, M. P. Berg, O. Petchey, C. Palmborg, and K. Huss-Danell. 2009. Long-term effects of plant diversity and composition on soil nematode communities in model grasslands. Ecology 90:90-99.
Wardle, D. A. 2002. Communities and ecosystems. Linking the aboveground and belowground components. Princeton University Press, Princeton, New Jersey, USA.

Wardle, D. A. 2006. The influence of biotic interactions on soil biodiversity. Ecology Letters 9:870-886.

Wardle, D. A., R. D. Bardgett, J. N. Klironomos, H. Setala, W. H. van der Putten, and D. H. Wall. 2004. Ecological linkages between aboveground and belowground biota. Science 304:1629-1633.

Wardle, D. A., K. I. Bonner, G. M. Barker, G. W. Yeates, K. S. Nicholson, R. D. Bardgett, R. N. Watson, and A. Ghani. 1999. Plant removals in perennial grassland: vegetation dynamics, decomposers, soil biodiversity, and ecosystem properties. Ecological Monographs 69:535-568.

Whitham, T. G., G. D. Martinsen, K. D. Floate, H. S. Dungey, B. A. Potts, and P. Keim. 1999. Plant hybrid zones affect biodiversity: tools for a genetic-based understanding of community structure. Ecology 80:416-428.

Yeates, G. W., T. Bongers, R. G. M. De Goede, D. W. Freckman, and S. S. Georgieva. 1993. Feeding-habits in soil nematode families and genera: an outline for soil ecologists. Journal of Nematology 25:315-331.

Zak, D. R., W. E. Holmes, D. C. White, A. D. Peacock, and D. Tilman. 2003. Plant diversity, soil microbial communities, and ecosystem function: Are there any links? Ecology 84: 2042-2050

\section{APPENDIX A}

Tables showing details of experimental design, characteristics of the plant communities in plots, soil organisms in food webs, and statistical analyses (Ecological Archives E091-211-A1).

\section{APPENDIX B}

A description of extraction protocols (Ecological Archives E091-211-A2).

\section{APPENDIX C}

Photograph made in 2003 of the experimental field with plots $(10 \times 10 \mathrm{~m}$ each) that were sown in 1996 with 15 or 4 species, or were not sown, and a close-up photograph of a typical plant community used for the experiment (Ecological Archives E091-211A3).

\section{APPENDIX D}

Figures showing ordination biplot diagrams of canonical correspondence analysis displaying the response of six organism groups to the interaction of sowing treatment and plant species identity; biomass of each feeding group of soil organisms in the rhizosphere soil of experimental L. corniculatus and $P$. lanceolata plants; and modeled nitrogen mineralization in the rhizosphere of experimental L. corniculatus and P. lanceolata plants (Ecological Archives E091-211-A4). 